\title{
Effect of Educational Intervention Based on Health Belief Model for Mothers about Prevention of Sudden Infant Death Syndrome
}

\author{
Amal Ahmed Ali Gamal El-deen ${ }^{1}$, Rahma Soliman Bahgat ${ }^{2}$, Mostafa Mohammed Awny ${ }^{3}$, \\ Sabah Mohamed Sharshour ${ }^{4}$. \\ ${ }^{1}$ Assistant Lecturer of Pediatric Nursing, Faculty of Nursing / Tanta University, Egypt. \\ ${ }^{2}$ Professor of Pediatric Nursing, Faculty of Nursing / Tanta University, Egypt. ${ }^{3}$ Professor of \\ Pediatrics, Faculty of Medicine / Tanta University, Egypt. ${ }^{4}$ Assistant Professor of Pediatric
} Nursing, Faculty of Nursing / Tanta University, Egypt

\begin{abstract}
Background; Sudden infant death syndrome is the sudden unexplained death of an infant less than one year of age which remains unexplained after a thorough investigation of clinical history. The aim of this study was to evaluate the effect of educational intervention based on Health Belief Model about prevention of sudden infant death syndrome. Subjects and Method: A convenience sampling of sixty mothers and their infants participated in the study. The study was conducted at Pediatric Medical Department and Pediatric Outpatient Clinic of Tanta Main University Hospital. Three tools were used to collect data: Sociodemographic characteristics and structured interview schedule, Reported Safe Sleep Questionnaire, and Health Belief Model of mothers related to sudden infant death syndrome. The results revealed that there was a statistically significant improvement of mothers' knowledge about Sudden Infant Death Syndrome after health education. The mean scores of mothers' total health belief constructs increased after health education. The study concluded that there was a positive significant improvement in mothers' knowledge, reported sleep practices as well as health beliefs about sudden infant death syndrome after health education. Recommendations: Nurses should provide mothers with information about safe sleep recommendations to prevent sudden infant death syndrome especially young and inexperienced mothers.
\end{abstract}

Keywords: Educational Intervention, Health Belief Model, Mothers, Prevention, Sudden Infant Death Syndrome. 


\section{Introduction}

Sudden infant death syndrome, known as cot death or crib death, is the sudden unexplained death of an infant less than one year of age. Sudden infant death syndrome usually occurs during sleep. There is usually no evidence of struggle and no noise produced. About $90 \%$ of cases occur before six months of age, it is most frequent between two and four months of age. It is more common in boys than girls. ${ }^{(1,2)}$

Predisposing factors for sudden infant death syndrome include premature birth, infant age, gender, ethnicity, and maternal exposure to smoking during and after pregnancy. Accidental suffocation from bed sharing or soft objects may also play a role. Other factors include socioeconomic status of parents, clinical problems during pregnancy and childbirth, sleeping in prone position, increased environmental temperature during sleep, infection, and stress. ${ }^{(3,4)}$

The recommendations of American Academy of Pediatrics include supine positioning, use of a firm sleep surface, breastfeeding, room-sharing without bedsharing, routine immunization, a pacifier use during bed time, and avoidance of soft bedding, overheating, and exposure to tobacco smoke and alcohol. Mothers' adherence to these recommendations depends on their knowledge and beliefs about SIDS. Thus, it is highly important to recognize mothers' beliefs and perceptions and how this may impact their behavior. The current study was conducted to evaluate the effect of educational intervention based on health belief model about prevention of sudden infant death syndrome. ${ }^{(5,6)}$

Health Belief Model is a psychological health behavior change model developed to explain health-related behaviors such as being screened for the early detection of asymptomatic diseases and receiving immunization. It was developed in 1950 by social psychologists at the United States Public Health Service and remains one of the best known and most widely used theories in health behavior research. It suggested that people's beliefs about health problems explain engagement or lack of engagement in health-promoting behaviors. ${ }^{(7)}$ Health Belief Model was used to develop effective interventions to change health-related behaviors. These Interventions aimed to increase perceived susceptibility and perceived seriousness of a health condition by providing 
information about prevalence, incidence, risk factors and the consequences of health condition. ${ }^{(8)}$

It also aimed to increase perceived benefits and decrease perceived barriers by providing information about the efficacy of various behaviors to reduce risk of health condition, identifying common perceived barriers, providing cues of action to encourage individuals to engage in healthpromoting behaviors. So, HBM can be modified and used to modify mothers' beliefs regarding SIDS. ${ }^{(9)}$

\section{Significance of the study}

Despite the release of guidelines by the AAP on safe infant sleep and public service campaigns aimed at reducing risk factors over the past 25 years, deaths due to SIDS and SUID are still the 4th leading causes of infant death in the United States. In 2001, SIDS becomes the third leading cause of post neonatal deaths that occur between the ages of 28 days and one year. According to the Centers for Disease Control and Prevention (CDC), the incidence of SIDS in 2017 was 35.4 per 100,000 live births in the United States. In 2018 , there were about 1,300 deaths due to SIDS, about 1,300 deaths due to unknown causes, and about 800 deaths due to accidental suffocation and strangulation in bed. ${ }^{(10,11,12)}$

There is scarcity of knowledge about SIDS in Egypt despite the worldwide recognition of this syndrome. Few records about the magnitude of the problem in Egypt are available as its diagnosis requires a complete autopsy which is difficult to be done for various reasons. Also estimation of the number of cases will not be accurate especially in places where recording of infant deaths isn't prevalent. There is a significant drop in infant mortality rates in Egypt from 63 deaths per 1000 live births in 1995 to 22 deaths per 1000 live births in 2014. ${ }^{(13,14)}$

\section{Aim of the study}

The study was conducted to evaluate the effect of educational intervention based on Health Belief Model about prevention of Sudden Infant Death Syndrome.

\section{Subjects and Method}

\section{Study design:}

A quasi-experimental research design was used in the present study.

\section{Study sitting:}

The study was carried out at Pediatric Medical Department and Pediatric Outpatient Clinic of Tanta Main University Hospital.

\section{Subjects:}


A convenience sample of 60 mothers and their infants were included in the study. The sample size calculation based on type I error 0.05 and power of test $90 \%$.

Three tools were used in the current study as follows:

Tool I: Sociodemographic characteristics and structured interview schedule: It was developed by the researcher after reviewing the related literature to collect information about mothers and their infants. It consisted of four main parts: Part I: Characteristics of the studied infants such as age and gender. It also included the physical measurements of the infant such as weight, length, head and chest circumference. Part II: Characteristics of the studied mothers such as age, level of education, occupation, and parity. Part III: Medical history of mothers including their present and past medical history.

Part IV: Mothers' knowledge about Sudden Infant Death Syndrome as definition, risk factors, and prevention.

\section{Scoring system:}

Correct and complete answers were given a score (2). Correct and incomplete answers were given a score (1). Wrong and/or no answer were given a score (zero). The total level of mothers' knowledge was scored as follows: Less than $60 \%$ was considered "poor". From $60 \%$ to less than $75 \%$ was considered "fair". From 75\% and more was considered "good".

\section{Tool II: Reported Safe Sleep}

Questionnaire: It was modified based on the American Academy of Pediatrics' recommendations for safe sleep and SIDS risk reduction to measure safe sleep practice recommendations among mothers such as: use of a firm sleep surface, the infant in supine position, avoid bed toys with infant, pacifier use during bed time, room sharing without bed sharing, avoid overheating, avoid smoking around the infant ${ }^{(15)}$.

\section{Scoring system:}

The Questionnaire consisted of 7 items and mothers were asked to use a Likert scale from 1to 3 as follows: never was scored (1), sometimes was scored (2), and always was scored (3). The total reported safe sleep practices recommendations was divided as follows: the total score above $75 \%$ was considered safe sleep practices. The total score less than $75 \%$ was considered unsafe sleep practices.

Tool III: Health Belief Model of mothers related to SIDS: It was 
developed by Hochbaum 1958, subsequently modified by the researcher, it consisted of five main constructs; including perceived susceptibility, perceived severity, perceived barriers, perceived benefits and cues to action. The original health belief model consisted of the following main constructs ${ }^{(6,7,16)}$ :

a. Perceived susceptibility: which included five items: the chances of SIDS affecting an infant are high, worry a lot about SIDS, SIDS is a big problem, know that infants die from SIDS, within first year, know that an infant could die of SIDS, and there is a good possibility that an infant may die from SIDS.

b. Perceived severity: which included five items: afraid to even think about SIDS, the thought of SIDS scares a lot, the SIDS is hopeless condition, thinking about SIDS makes heart beats faster, and SIDS is a big deal.

c. Perceived benefits: which included four items: Placing infants on their back to sleep prevents SIDS, it's best for infants to sleep in crib or bassinet to prevent SIDS, don't worry so much about SIDS when infants sleep on their back, and not anxious about SIDS when an infant sleeps in own crib. d. Perceived barriers: which included six items: can't reduce the chance of infants dying from SIDS, the best place for infants to sleep is in the bed with their mother, infants are more comfortable in sleeping on their stomach, family/friends would make fun if put infants to sleep on their back, putting an infant on their back to sleep would require starting a new habit, which is difficult, and prefer placing an infant on their stomach to sleep because it's easier.

e. Cues to action: which included three items: receiving much of infant care information from health professionals such as doctors and nurse, receiving much of infant care information from family members, and receiving much of infant care information from friends.

\section{Health Belief Model scoring system:}

The Questionnaire consisted of (23) items Used five point Likert scale (ranging from strongly agree to strongly disagree) to measure perceptions of behavior related to Sudden Infant Death Syndrome.

The scoring system for perceived benefits and cues to action: Strongly agree (5), agree (4), natural (3), disagree (2), and strongly disagree (1). 
The scoring system for perceived susceptibility, perceived severity, and perceived barriers was reversed coded: Strongly agree was scored (1), agree, natural (3), disagree (4), strongly disagree(5).

Each item of Health Belief Model was scored as follows: Perceived susceptibility included five questions with a minimum score of (5) and a maximum score of (25). Perceived severity included five questions with a minimum score of (5) and a maximum score of (25). Perceived benefits included four questions with a minimum score of (4) and a maximum score of (20). Perceived barriers included six questions with a minimum score of (6) and a maximum score of (30). Cues to action included three questions with a minimum score of (3) and a maximum score of (15).

\section{The total score of all items of Health} Belief Model was calculated and classified as follows: Negative belief if the total score of mothers' health beliefs was less than $60 \%$ of the total belief scores and positive belief if the total score of mothers' health beliefs was more than $60 \%$ of the total belief scores.

Method:
Mothers' consent to participate in this study was obtained after explaining the aim of the study and receiving explanation about the nature of the study; their participation in the study was voluntary.The obtained information was confidential and used only for purpose of the study. The tools of the study were tested for its content validity by five experts in the pediatric nursing field. Modifications were carried out accordingly. A pilot study was carried out on $10 \%$ of the study sample to test clarity and applicability of the study tools then, the necessary modification was done. The pilot study was excluded from the study sample.

\section{Implementation of the study: The study} was conducted through four phases:

1. Assessment phase :It was carried out by the researcher to:

- Collect information about the studied mothers and their infants .

- Assess mothers' knowledge about SIDS, reported safe sleep practices, and their health beliefs about SIDS (Tool I, II, III). In this phase, the researcher interviewed the mothers to collect baseline data. At the beginning of the interview the researcher greeted the mothers, introduced herself to each mother, explained all information 
about the study purpose, duration, and activities and took their oral consent to participate in the study .

\section{Planning phase: Educational} intervention was developed after extensive review of the related literature. It was designed according to mothers' educational needs assessment which included the following:

-Setting objectives.

-Preparation of the content which covered the reason behind the application of the educational intervention .

-The educational intervention module was designed by the researcher in the form of booklet. It was written in English then translated into simple Arabic language to be suitable to all mothers' level of understanding and education. It was given to all mothers who participated in the study .

- Different methods and materials for educational intervention were used including lectures, group discussion, PowerPoint, and colored posters.

3. Implementation phase: The studied mothers were divided into six subgroups, with ten mothers in each subgroup. The educational intervention was carried out for each subgroup separately through conduction of successive sessions. The average time for the completion of each session was 30 minutes. Sometimes, it was difficult to collect ten mothers at the same time. In this case, the sessions were given to the available number of mothers according to their attendance to the Pediatric Medical Department or Pediatric Outpatient Clinic and their follow up schedule. Each session started with a feedback about the previous session and the objectives of the new session. All mothers' questions were answered throughout the sessions.

\section{The educational intervention sessions were carried out as follows:}

a. The first session: It focused on definition, most common age of occurrence and incidence of SIDS.

b. The second session: It focused on causes, risk factors, and prevention of SIDS .

c. The third session: It focused on safe sleep recommendations according to the American Academy of Pediatrics' recommendations for safe sleep and SIDS risk reduction.

d. The fourth session: It focused on the health beliefs, assumptions and incorrect beliefs about SIDS and its effect on prevention of SIDS. This session also focused on issues that may 
be a barrier to safe sleep practices and proper position for sleep to prevent SIDS.

4. Evaluation phase: The researcher assessed mothers' knowledge, reported safe sleep practices, and health beliefs regarding SIDS three times before the educational intervention, immediately after (immediate follow up), and one month after the implementation of health education (short term follow up) by using (Tool I, II, III). The evaluation was done one time before the implementation of health education to assess mothers' knowledge, reported safe sleep practices, and health beliefs regarding SIDS. It was done immediately after the implementation of health education to assess mothers' feedback and level of understanding of the given knowledge. Reevaluation was done for the 3rd time after one month of implementation of the health education to evaluate the mothers' retention of knowledge, their consistency in following safe sleep practices, and to evaluate any change of their health beliefs regarding SIDS with time as well.

\section{Statistical analysis:}

The collected data was organized, tabulated and statistically analyzed using SPSS software (Statistical Package for the
Social Sciences, version 16, SPSS Inc. Chicago, IL, USA). For quantitative data, the range, mean and standard deviation were calculated. For qualitative data, comparison between two groups and more was done using Chi-square test (X2). For comparison between means of two groups of parametric data of independent samples, student t-test was used. For comparison between more than two means of parametric data, $F$ value of ANOVA test was calculated for parametric data, where Scheffe test was performed to compare between each two means if $F$ value was significant. Significance was adopted at $\mathrm{P}<0.05$ for interpretation of results of tests of significance ${ }^{(17)}$.

\section{Result}

Table (1): In relation to age, it was observed that $38.3 \%$ of the studied infants' age was from 5 to less than 9 months, while $35 \%$ of them were from 9 to less than 12 months old with mean age $6.70 \pm$ 3.033. Regarding sex of the studied infants, half of them $(50 \%)$ were males. In relation to birth order, $40 \%$ of the studied infants were the $2^{\text {nd }}$ birth in their family, while $31.7 \%$ were the 1 st birth.

Regarding gestational age of the studied infants, nearly two thirds $(63.3 \%)$ of them were delivered at 37-39 weeks of 
gestation, while $36.3 \%$ of them were delivered at 40-42 weeks of gestation with mean gestational age $39.20 \pm 1.204$. It was observed that half of the studied infants' weight at birth was from 2 to less than 3 $\mathrm{kg}$, while $46.7 \%$ was from 3 to less than 4 $\mathrm{kg}$ with mean birth weight $3.01 \pm 0.493$. The majority $(81.7 \%)$ of the studied infants-had not exposed to any problems during labor, but $13.3 \%$ of them had exposed to cyanosis due to prolonged labor.

Table (2): The table reveals that the age of nearly three quarters of the studied mothers $(70 \%)$ was $>20-30$ years old, while one quarter of them $(26.7 \%)$ were more than thirty years old with mean age $28.066 \pm$ 4.47. In relation to the educational level of the studied mothers, almost one third of them $(35 \%)$ had secondary education and one third of them $(30 \%)$ can read and write.

More than half of the studied mothers didn't work. As regards parity of the studied mothers, the majority of mothers were multiparous. Less than half of them $(46.7 \%)$ were multiparous who had given birth two times. One quarter of them had given birth three times, while one third of them $(21.6 \%)$ were primiparous.
Table (3) It was evident that all mothers (100\%) had poor knowledge about SIDS before health education compared to $100 \%$ and $95 \%$ of them had good knowledge immediately and one month after health education respectively with highly significant difference $(\mathrm{P}$ - value 0.0001 and $\mathrm{x}^{2}$ value 184.62). The table reveals that the total knowledge mean scores were $18.91 \pm 9.78,56.05 \pm 1.56$, and 49.15 \pm 2.94 before, immediately, and one month after health education respectively with statistically significant difference $(\mathrm{P}$ - value 0.0001).

The table also reveals that there was change in total knowledge mean scores immediately after than before health education with mean \pm SD was $37.14 \pm$ 9.82 with statistically significant difference (P- value 0.0001). In addition, there was change in mothers' total knowledge mean scores one month after than before health education with mean \pm SD was $30.24 \pm$ 10.07 with statistically significant difference ( $\mathrm{P}$ - value 0.0001).

Table (4): The table reveals that more than half of mothers $(58.3 \%)$ stated that they sometimes use firm sleep surface before health education, while $100 \%$ and $76.7 \%$ of them viewed that the always use firm sleep surface immediately and one month 
after health education respectively with statistically significant difference $(P$ value 0.0001 and $x^{2}$ value 76.233).

It was found that $88.3 \%$ of mothers sometimes put the infant in supine position before health education, compared to $88.3 \%$ and $73.3 \%$ of them always put the infant in supine position immediately and one month after health education respectively. More than one third of mothers $(41.7 \%)$ stated that they never avoid bed toys with infant during sleep before health education. On the other hand, most of mothers $(91.7 \%)$ stated that they always avoid bed toys with infant during sleep immediately and one month after health education with statistically significant difference $(\mathrm{P}$ value 0.0001 and $x^{2}$ value 63.333)

Nearly two thirds of mothers $(70 \%)$ said that they never use pacifier to infant during bedtime before health education. on the other hand, one third of them (30\%) always use pacifier during bedtime immediately after health education, and $63.4 \%$ of them stated that they sometimes use pacifier during bed time with statistically significant difference $(\mathrm{P}$ value 0.0001 and $x^{2}$ value 147.633). It was evident that $38.3 \%$ of mothers stated that they share room and bed with their infants, while $55 \%$ of them sometimes share room without bed sharing before health education. More than two thirds of mothers (73.3\% and $71.7 \%$ ) are always sharing room without bed sharing immediately and one month after health education with statistically significant difference $(P$ value 0.0001 and $x^{2}$ value 82.861).

In relation to negative smoking, $71.7 \%$ of mothers exposed to negative smoking around their infants before health education, while $96.7 \%$ and $95 \%$ of them always avoid smoking around infants immediately and one month after health education with statistically significant difference $\left(\mathrm{P}\right.$ value 0.0001 and $\mathrm{x}^{2}$ value 158.48).

Table (5): It was evident that the majority $(98.3 \%)$ of reported sleep practices of the studied mothers were unsafe before health education compared to $100 \%$ and $91.6 \%$ them were safe immediately and one month after health education respectively with statistically significant difference (Pvalue 0.0001$)$.

The table reveals that there was change in total practice mean scores immediately after than before health education with mean $\pm \mathrm{SD}$ was $7.72 \pm 1.85$ with statistically significant difference $(\mathrm{P}$ - value 0.0001). In addition, there was change in 
mothers' total practice means scores one month after than before health education with mean $\pm \mathrm{SD}$ was $6.73 \pm 2.32$ with statistically significant difference $(\mathrm{P}$ - value 0.0001 and $\mathrm{x}^{2}$ value 155.706).

Table (6): It was observed that all mothers $(100 \%)$ had negative beliefs about SIDS before health education. All mothers' beliefs $(100 \%)$ had changed to positive immediately and one month after health education with statistically significant difference $\left(\mathrm{P}\right.$ - value 0.0001 and $\mathrm{x}^{2}$ value 180.00). The mean scores of total mothers' beliefs were $48.96 \pm 2.84, \quad 109.2 \pm 2.04$, $106.75 \pm 2.43$ before, immediately, and one month after health education respectively.

The table reveals that total mothers' health belief scores had changed immediately after than before health education with mean $\pm \mathrm{SD}$ is $60.25 \pm 3.07$ with statistically significant difference (P- value 0.0001). Finally, total mothers' health belief scores had changed one month after than before health education with mean \pm $\mathrm{SD}$ is $57.78 \pm 3.43$ with statistically significant difference (P- value 0.0001).

Figure (1): It was found that the majority of mothers $(98.3 \%)$ had poor knowledge and followed unsafe sleep practices before health education, compared to all mothers (100\%) had good knowledge and followed safe sleep practices immediately after health education.

Figure (2): It was observed that all mothers $(100 \%)$ with poor knowledge had negative health beliefs about SIDS before health education, while all of them $(100 \%)$ had good knowledge and positive health beliefs immediately after the health education. On the other hand, the majority of mothers (95\%) had positive health beliefs and good knowledge one month after health education.

Figure (3): It was found that there was a negative non- significant correlation total mothers' knowledge and total safe sleep practices before health education but the correlation became positive and significant immediately after health education (Pvalue 0.046).

A negative significant correlation was observed between total mothers' knowledge and total health beliefs before health education (P- value 0.006), while it became positive and significant immediately and one month after health education where $\mathrm{P}$ - value $=0.003$ and 0.022-respectively 
Table (1): Percentage distribution of the studied infants according to their sociodemographic characteristics.

\begin{tabular}{|c|c|c|}
\hline \multirow[b]{2}{*}{ Sociodemographic characteristics } & \multicolumn{2}{|c|}{$(\mathrm{n}=60)$} \\
\hline & No & $\%$ \\
\hline \multicolumn{3}{|l|}{ Age (Month): } \\
\hline $1-<5$ & 16 & 26.7 \\
\hline $5-<9$ & 23 & 38.3 \\
\hline$\geq 9-12$ & 21 & 35.0 \\
\hline Range & \multicolumn{2}{|c|}{$1-12$} \\
\hline Mean \pm SD & \multicolumn{2}{|c|}{$6.70 \pm 3.033$} \\
\hline Sex: & & \\
\hline Male & 30 & 50.0 \\
\hline Female & 30 & 50.0 \\
\hline \multicolumn{3}{|l|}{ Birth order: } \\
\hline First & 19 & 31.7 \\
\hline Second & 24 & 40.0 \\
\hline Third & 13 & 21.7 \\
\hline Fourth & 4 & 6.7 \\
\hline \multicolumn{3}{|l|}{ Gestational age (Weeks): } \\
\hline $37-39$ & 38 & 63.3 \\
\hline $40-42$ & 22 & 36.7 \\
\hline Range & \multirow{2}{*}{\multicolumn{2}{|c|}{$\begin{array}{c}37-42 \\
39.20 \pm 1.204\end{array}$}} \\
\hline Mean \pm SD & & \\
\hline \multicolumn{3}{|l|}{ Birth weight $(\mathrm{Kg})$ : } \\
\hline $2-<3$ & 30 & 50.0 \\
\hline $3-<4$ & 28 & 46.7 \\
\hline$\geq 4-5$ & 2 & 3.3 \\
\hline Range & \multirow{2}{*}{\multicolumn{2}{|c|}{$\begin{array}{c}2-4.5 \\
3.01 \pm 0.493\end{array}$}} \\
\hline Mean \pm SD & & \\
\hline Problems during labor: & & \\
\hline No problems & 49 & 81.7 \\
\hline Cyanosis due to prolonged labor & 8 & 13.3 \\
\hline Head trauma & 3 & 5.0 \\
\hline
\end{tabular}


Table (2): Percentage distribution of the studied mothers according to their sociodemographic characteristics.

\begin{tabular}{|c|c|c|}
\hline Sociodemographic & \multicolumn{2}{|c|}{$(n=60)$} \\
\hline Characteristics & No & $\%$ \\
\hline \multicolumn{3}{|l|}{-Age (years): } \\
\hline$\leq 20$ & 2 & 3.3 \\
\hline$>20-30$ & 42 & 70.0 \\
\hline$>30$ & 16 & 26.7 \\
\hline Range & \multicolumn{2}{|c|}{$19-38$} \\
\hline Mean \pm SD & \multicolumn{2}{|c|}{$28.066 \pm 4.47$} \\
\hline \multicolumn{3}{|l|}{-Educational level: } \\
\hline Illiterate & 4 & 6.7 \\
\hline Read and write & 18 & 30.0 \\
\hline Secondary education. & 21 & 35.0 \\
\hline University education. & 17 & 28.3 \\
\hline \multicolumn{3}{|l|}{-Mothers' occupation: } \\
\hline Working & 29 & 49.3 \\
\hline Not working & 31 & 51.7 \\
\hline \multicolumn{3}{|l|}{-Parity: } \\
\hline One & 13 & 21.6 \\
\hline Two & 28 & 46.7 \\
\hline Three & 15 & 25.0 \\
\hline Four & 4 & 6.7 \\
\hline
\end{tabular}


Table (3): Percentage distribution of the studied mothers according to levels and mean scores of total knowledge about Sudden Infant Death Syndrome.

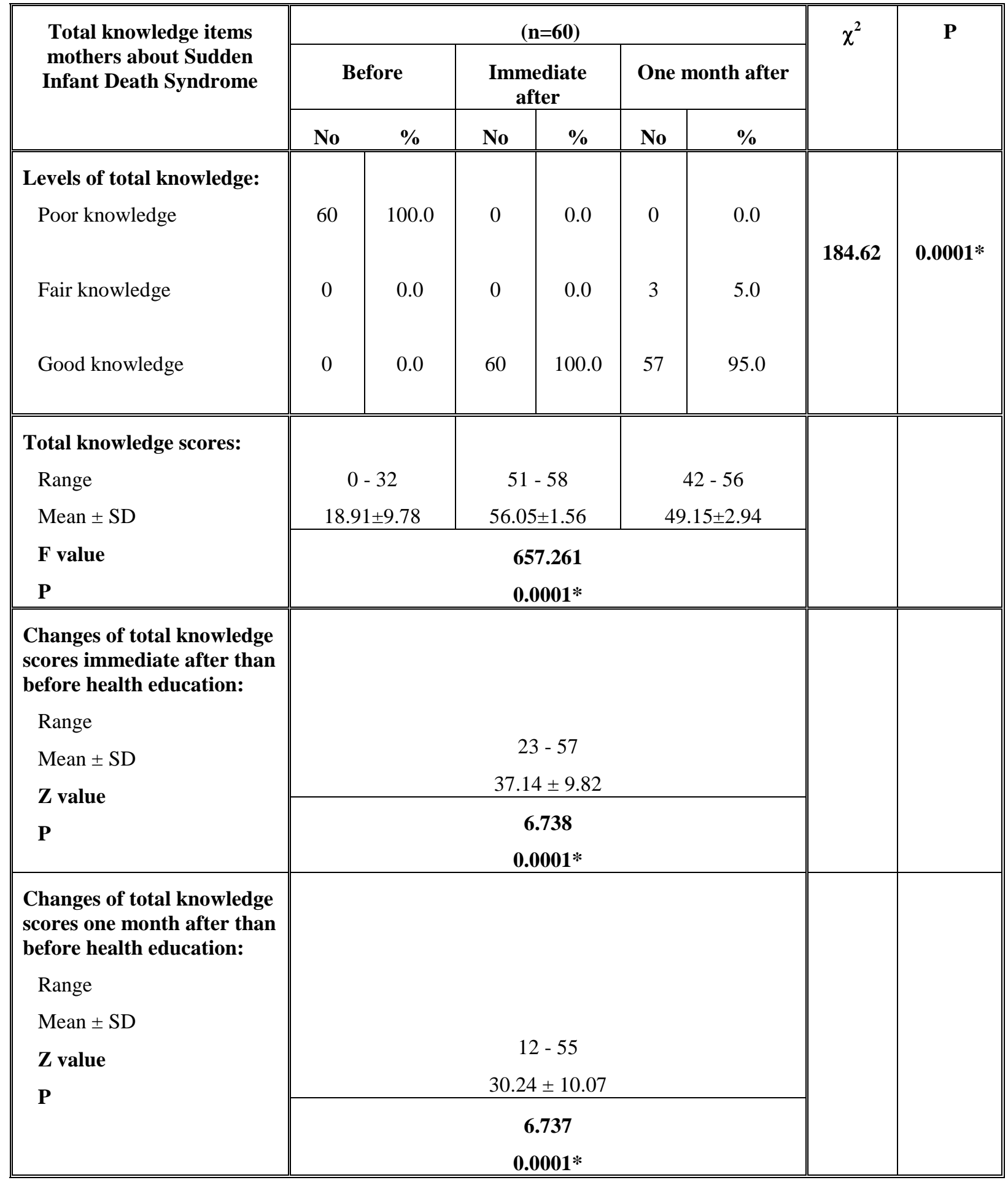


Table (4): Percentage distribution of the studied mothers according to reported safe sleep practices.

\begin{tabular}{|c|c|c|c|c|c|c|c|c|c|c|c|c|c|c|c|c|c|c|c|c|}
\hline \multirow{4}{*}{$\begin{array}{l}\text { Mothers' reported safe } \\
\text { sleep practices }\end{array}$} & \multicolumn{18}{|c|}{$(n=60)$} & \multirow{4}{*}{$\chi^{2}$} & \multirow{4}{*}{$\mathbf{P}$} \\
\hline & & & & & & & & & ImI & diate & & & & & ter 0 & e mor & & & & \\
\hline & \multicolumn{2}{|c|}{ Never } & \multicolumn{2}{|c|}{ Sometimes } & \multicolumn{2}{|c|}{ Always } & \multicolumn{2}{|c|}{ Never } & \multicolumn{2}{|c|}{ Sometimes } & \multicolumn{2}{|c|}{ Always } & \multicolumn{2}{|c|}{ Never } & \multicolumn{2}{|c|}{$\begin{array}{l}\text { Sometime } \\
\mathrm{s}\end{array}$} & \multicolumn{2}{|c|}{ Always } & & \\
\hline & No & $\%$ & No & $\%$ & No & $\%$ & No & $\%$ & No & $\%$ & No & $\%$ & No & $\%$ & No & $\%$ & No & $\%$ & & \\
\hline Use of a firm sleep surface & 17 & 28.4 & 35 & 58.3 & 8 & 13.3 & 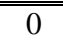 & 0.0 & 0 & 0.0 & 60 & 100.0 & 6 & 10.0 & 8 & 13.3 & 46 & 76.7 & 76.233 & 0.0001* \\
\hline $\begin{array}{l}\text { The infant in supine } \\
\text { position, }\end{array}$ & 5 & 8.3 & 53 & 88.3 & 2 & 3.4 & 2 & 3.4 & 5 & 8.3 & 53 & 88.3 & 6 & 10.0 & 10 & 16.7 & 44 & 73.3 & 15.38 & 0.0001* \\
\hline $\begin{array}{l}\text { Avoid bed toys with } \\
\text { infant. }\end{array}$ & 25 & 41.7 & 27 & 45.0 & 8 & 13.3 & 0 & 0.0 & 5 & 8.3 & 55 & 91.7 & 0 & 0.0 & 5 & 8.3 & 55 & 91.7 & 63.333 & 0.0001* \\
\hline $\begin{array}{l}\text { Pacifier use during bed } \\
\text { time. }\end{array}$ & 42 & 70.0 & 15 & 25.0 & 3 & 5.0 & 5 & 8.3 & 37 & 61.7 & 18 & 30.0 & 5 & 8.3 & 38 & 63.4 & 17 & 28.3 & 147.633 & $0.0001 *$ \\
\hline $\begin{array}{l}\text { Room sharing without bed } \\
\text { sharing. }\end{array}$ & 23 & 38.3 & 33 & 55.0 & 4 & 6.7 & 0 & 0.0 & 16 & 26.7 & 44 & 73.3 & 2 & 3.3 & 15 & 25.0 & 43 & 71.7 & 82.861 & $0.0001 *$ \\
\hline Avoid overheating. & 25 & 40.0 & 16 & 26.7 & 20 & 33.3 & 0 & 0.0 & 11 & 18.3 & 49 & 81.7 & 0 & 0.0 & 11 & 18.3 & 49 & 81.7 & 98.800 & $0.0001 *$ \\
\hline $\begin{array}{l}\text { Avoid smoking around the } \\
\text { infant. }\end{array}$ & 43 & 71.7 & 16 & 26.7 & 1 & 1.7 & 0 & 0.0 & 2 & 3.3 & 58 & 96.7 & 0 & 0.0 & 3 & 5.0 & 57 & 95.0 & 158.48 & $0.0001 *$ \\
\hline
\end{tabular}


Table (5): Percentage distribution of the studied mothers according to levels and mean scores of total reported safe sleep practices.

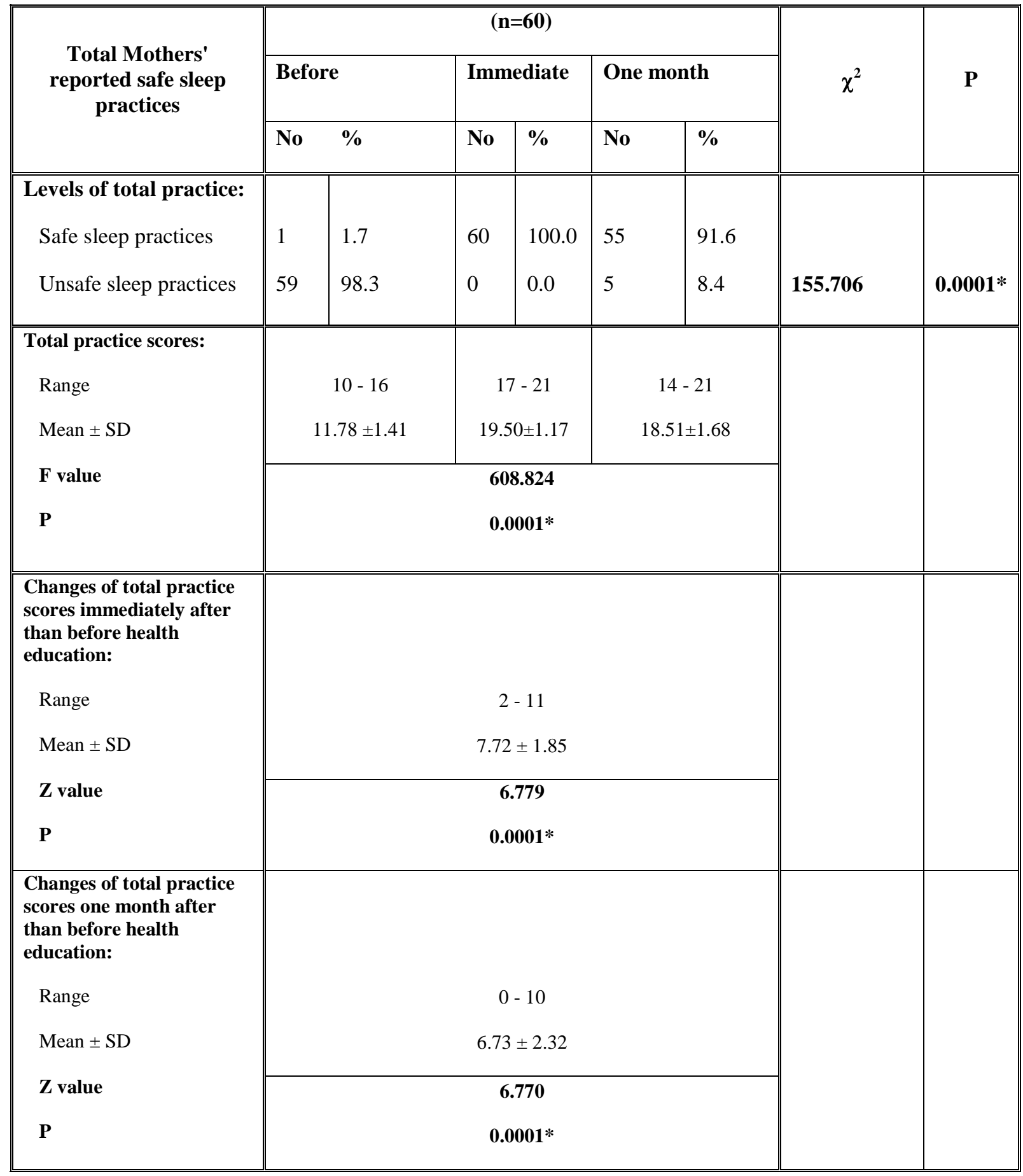

*Statistically significant difference at $(\mathbf{P}<\mathbf{0 . 0 5})$ 
Table (6): Percentage distribution of levels and mean scores of total mothers' health beliefs about Sudden Infant Death Syndrome.

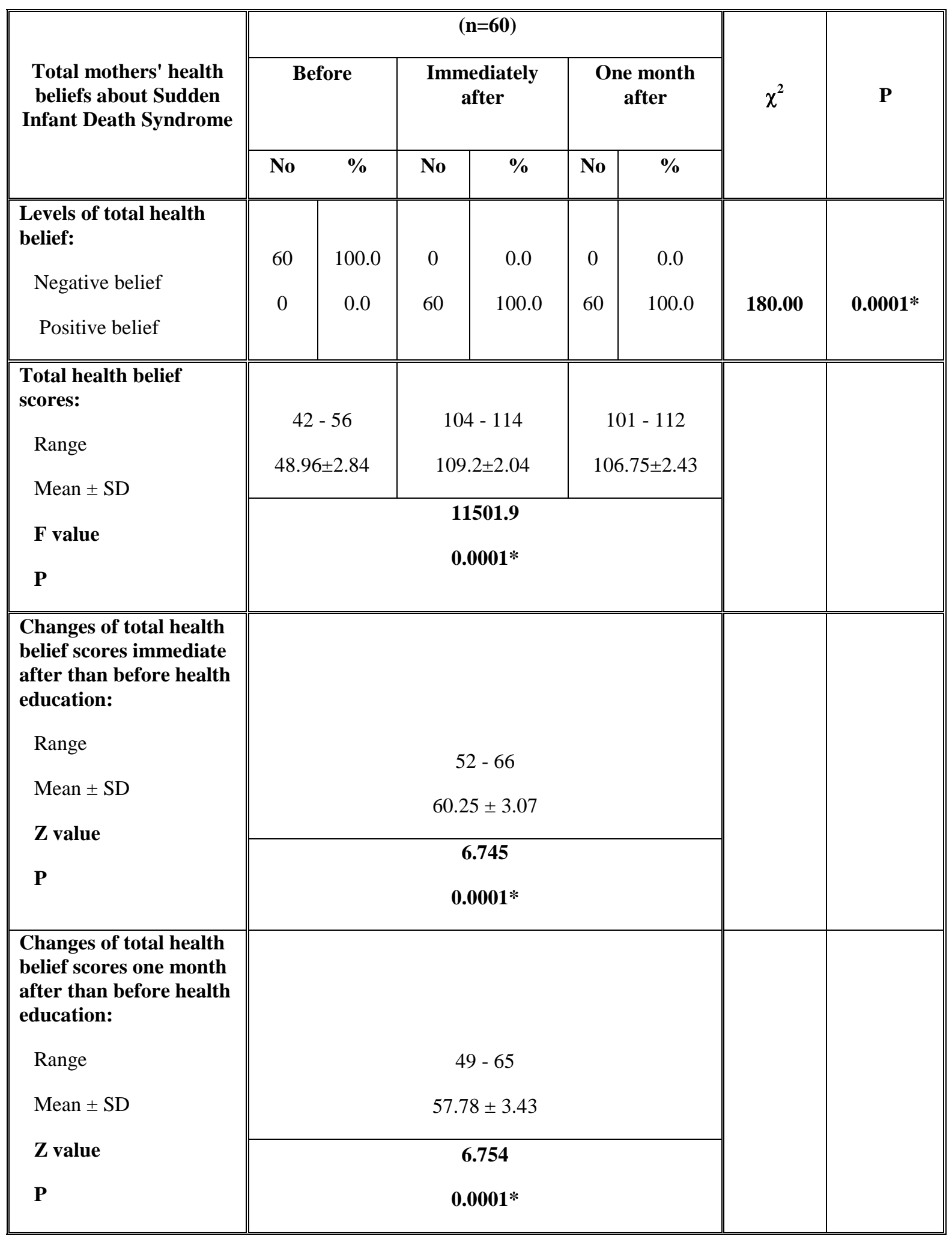

*Statistically significant difference at $(\mathbf{P}<0.05)$

Vol. 20 No. 1 February, 2021 


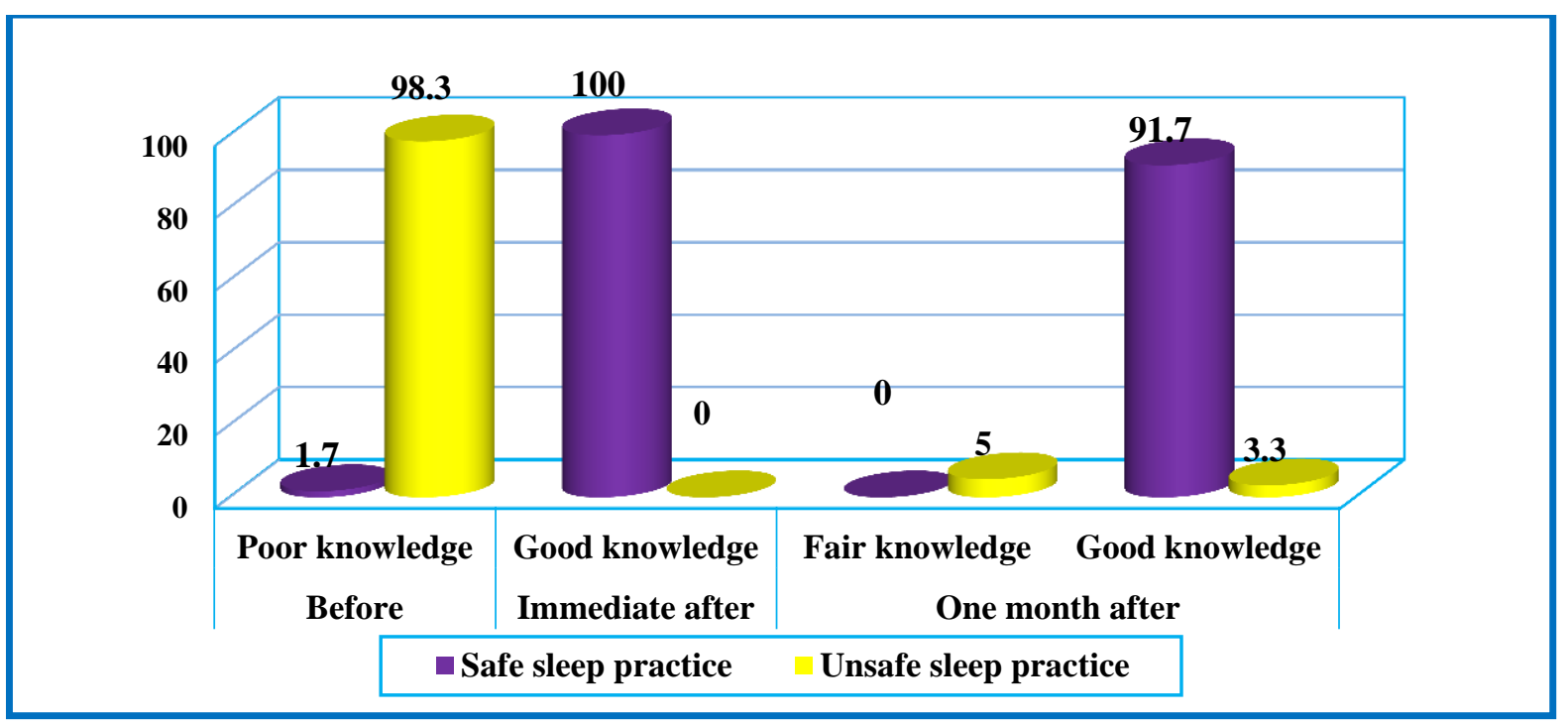

Figure (1): Relation between total mothers' knowledge and total reported safe sleep practices about Sudden Infant Death Syndrome.

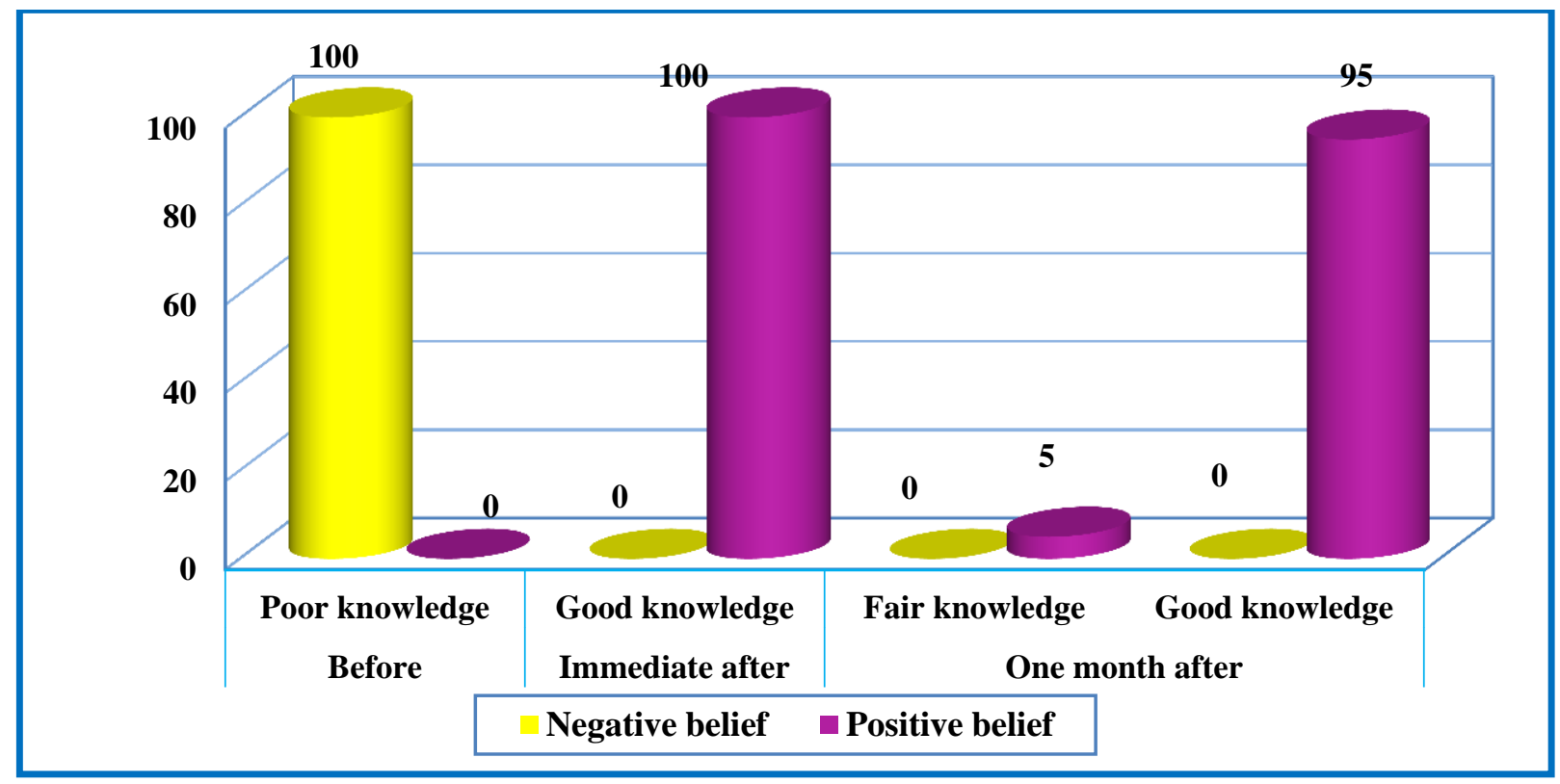

Figure (2): Relation between total mothers' knowledge and health beliefs about Sudden Infant Death Syndrome. 


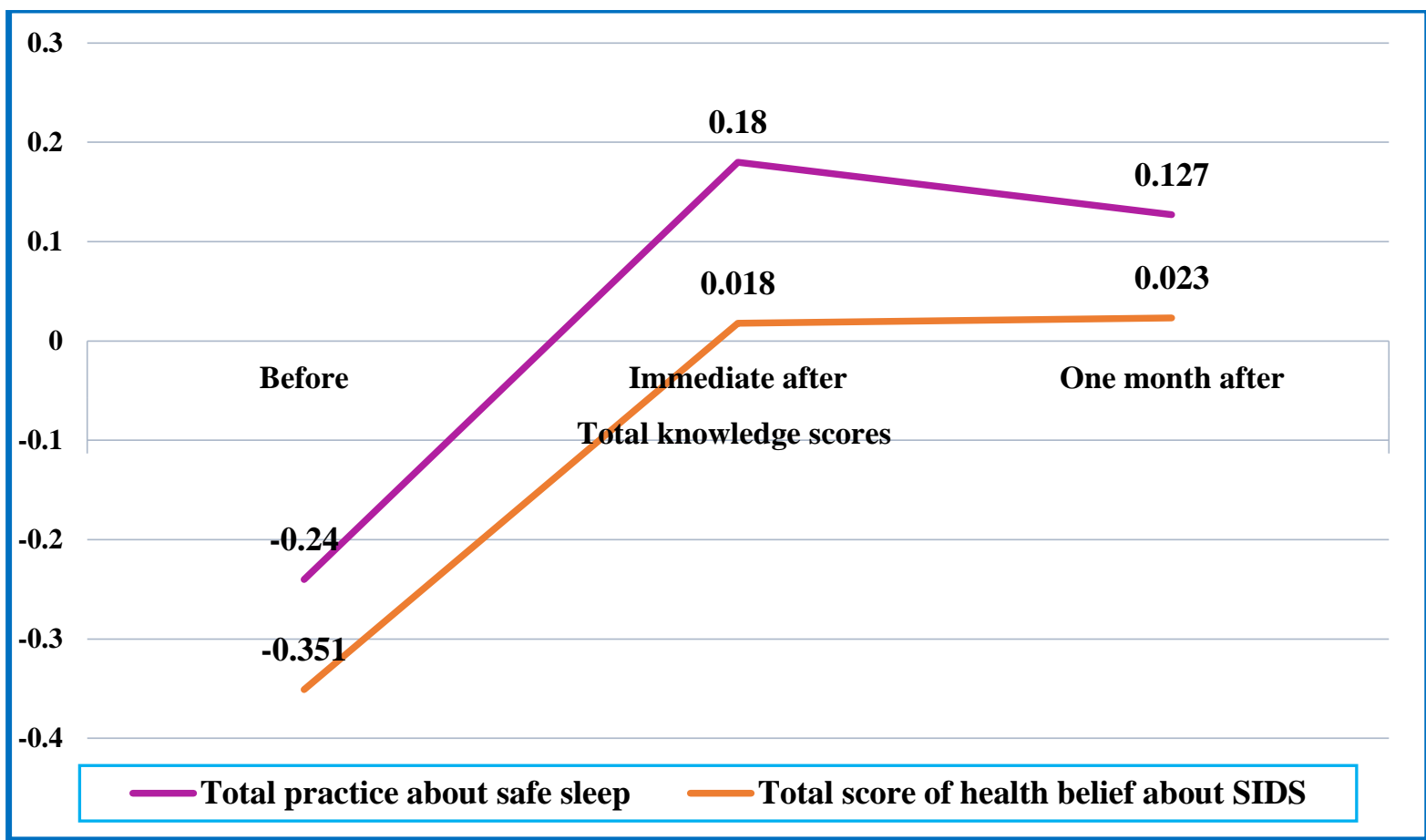

Figure (3): Correlation between total mothers' knowledge, total reported safe sleep practices and health beliefs about Sudden Infant Death Syndrome. 


\section{Discussion}

Sudden Infant Death Syndrome is the third leading cause of infants' mortality. It is the most common cause of death in infants from one month to one year. SIDS is not a new problem, it occurs worldwide across many different cultures. It is a serious problem, and in spite of all the research conducted in recent years, it remains to be unpredictable. There are no tests can predict that an infant may die from SIDS. The World Health Organization developed a category for SIDS, recognizing it as an official international cause of death in 2011. ${ }^{(18)}$

Although the exact cause remains unknown, SIDS occurs due to an interaction among intrinsic vulnerability, development, and environmental challenges. There is a relationship between SIDS and prone sleep position. It has been identified as an important risk factor for SIDS. The American Academy of Pediatrics (AAP) defined standard guidelines for infant positioning and sleep environment to reduce the risk of SIDS. Their recommendations are expanded from being only SIDS-focused to focus on a safe sleep environment that can reduce the risk of all sleep-related infant deaths including SIDS Mothers should be aware of such problem and its relation to prone sleep position. ${ }^{(19,20)}$

Regarding sociodemographic characteristics of the studied infants, in relation to age, the present study revealed that the majority of the studied infants' age was from five to less than twelve months. From the researchers' point of view, this is because the ages of the studied subjects were infants less than one year which is the common age for SIDS. This result of Botia et al (2020) was in agreement with the present study as they found that nearly half of infants were aged six to eleven months. (21). The result of Caraballo et al (2016) was also congruent with the present study as they found that most of infants' age ranged from two to twelve months. ${ }^{(22)}$

Regarding sex of the studied infants in the current study, it was observed that half of them were males. From the researcher's point of view, they were the available infants in the pediatric medical department and pediatric outpatient clinic and their mothers accepted to participate in the study and this occurred by chance. The result of Bezerra et al (2015) was in agreement with the present study as they reported that nearly half of infants were males ${ }^{(23)}$. The result of Isezuo et al (2017) was also congruent with the current study as they 
found that more than half of infants were males (24). On the other hand, Elsobkey (2018) was incongruent with the present study result and reported that the majority of the studied infants were males. ${ }^{(25)}$

As for sociodemographic characteristics of the studied mothers, the present study reported that nearly three quarters of mothers were aged $>20-30$ years old. This may be due to early marriage of most studied mothers. The result of the current study is the same as Bezerra et al (2015) who found that the majority of mothers were aged 20 years old and over. ${ }^{(23)}$ On the contrary, the present study was incongruent with Elsobkey (2018) who found that the age of the majority of mothers was 18- <23 years old. ${ }^{(25)}$ Botia (2020) also was against the present study and found that the majority of mothers were aged 34 years old and over. ${ }^{(21)}$

In addition, Isezuo et al (2017) found that the mothers' age was ranging from 17- 45 years old ${ }^{(24)}$. Another study conducted by Park (2012) showed that the age of the mothers ranged from 17 to 39 years old. ${ }^{(26)}$ The result of the current study also stands in contrast to Caraballo (2016) who stated that nearly all mothers were teenage mothers. ${ }^{(22)}$

Regarding mothers' level of education, the current study concluded that the studied mothers' educational level was divided into three levels. One third of them can read and write, one third of them were secondary education, and nearly one third of them were university education. This can be explained that marriage occurred early for all levels of education of the studied mothers. These study results were in accordance with the findings of Park (2012) who reported that one third of mothers were secondary education, but nearly half of them were university education. (26)

Caraballo (2016) and Mims (2014) results were against the current study results as they found that the majority of mothers who participated in their studies were secondary education ${ }^{(22,16)}$. Mims (2014) stated that only one third of mothers were university education ${ }^{(16)}$. Botia et al (2020) also disagreed with the results of the current study and found that two thirds of mothers had university degree. (21) The current study result was also incongruent with Isezuo et al (2017) who found that the majority of mothers were secondary education. (24) Another study conducted by Elsobkey (2018) showed that more than half of mothers were secondary education. ${ }^{(25)}$

As regards parity of the studied mothers, nearly three quarters of mothers were 
multiparous and nearly one quarter of mothers were primiparous. This result stands in contrast to Elsobkey (2018) who found that $80 \%$ of the mothers were primiparous while $20 \%$ of them were multiparous. ${ }^{(25)}$ Mims (2014) reported that the majority of mothers had one child, while small percentage of mothers had 3-5 children. ${ }^{(16)}$

Before the health education almost all mothers had poor knowledge about sudden infant death syndrome. The researcher interpreted this as it is uncommon terminology and mothers didn't receive any health teaching about sudden infant death syndrome during pregnancy and after delivery. Bezerra et al (2015) supported the current study; they found that the majority of mothers had no knowledge about sudden infant death syndrome. (23)

The result of Elsobkey (2018) was consistent with the current study and indicated that the majority of mothers had poor knowledge and weren't aware of the risk factors before the health education. ${ }^{(25)}$ Another study carried out by Isezuo et al (2017) revealed that mothers had poor knowledge as only one third of them heard about sudden infant death syndrome. (24)

The current study figured out that there was a significant improvement in mothers' total knowledge about sudden infant death syndrome after the implementation of health education. From the researchers' point of view, this improvement in mothers' knowledge was due to their urgent desire to know more information about this syndrome, its risk factors, and prevention of its occurrence to their infants.

From the researchers' point of view, the mothers' educational level played an important role in improvement of their knowledge as more than two thirds of them were secondary and university education. The majority of mothers had good knowledge after one month of health education. Abdeyazdan et al (2017) reached the same result and showed that the mean score of knowledge in mothers had increased immediately after health education, and this increase continued to 2 months after the intervention. (27) In addition, a study conducted by Rungtiwa et al (2012) supported the current study and demonstrated that mothers involved in the education program had increased knowledge and skills about how to care for their infants. ${ }^{(28)}$ Furthermore, Elsobkey (2018) agreed with the present study and stated that mothers had good knowledge after health education. ${ }^{(25)}$

Safe sleep practices are very important factors to prevent sudden infant death 
syndrome based on the American Academy of Pediatrics' recommendations for safe sleep. Safe sleep practices includes supine sleep position, using firm sleep surface, avoiding bed toys with infant, pacifier use during bed time, room sharing without bed sharing, avoiding overheating, and avoidance of smoking around the infant. Supine sleep position is the most important sleep practice; it did not increase the risk of aspiration and choking in infants, even those with gastroesophageal reflux, because infants have airway anatomy and mechanisms that protect against aspiration. Preterm infants should be placed supine as soon as possible more than full term infants. ${ }^{(29)}$

The present study clarified that the majority of mothers did not follow safe sleep practices before health education. Regarding sleep position, the majority of studied mothers preferred non supine sleep positions for their infants such side lying or prone sleeping position. Reasons for practicing non supine sleep positions reported by mothers in the current study were fear of choking, for infant comfort, and safety on supine position. Mothers also mentioned that placing the infant to sleep on non-supine positions decreases the risk of aspiration in case of regurgitation and vomiting.
The researcher illustrated this as the source of information in those mothers was not from medical personnel and they had poor knowledge about safe sleep position to prevent sudden infant death syndrome. Few mothers reported that their physician had recommended side lying position for sleep as a treatment for reflux.

Bezerra et al (2015) agreed with the present study as they mentioned that the majority of mothers practiced prone or side position for sleep. ${ }^{(23)}$ Botia et al (2020) also agreed with the present study, they found that more than half of the infants did not sleep in the supine position because the pediatricians did not recommend this position for mothers during discharge of infant from hospital. ${ }^{(21)}$ Elsobkey (2018) was in accordance the present study and indicated that majority of mothers never follow safe sleep practices especially supine position before health education. ${ }^{(25)}$ In addition, Isezuo et al (2017) clarified that sleep position in half of infants was side lying, while the others practiced no particular position for their infants during sleep. ${ }^{(24)}$

Moon et al (2016) stated that mothers who reported seeing nurses placing infants on prone position were most likely to imitate them and placed their infants to sleep in prone position as well. ${ }^{(30)}$ Fox et al (2014) 
mentioned that mothers were most likely to practice sudden infant death syndrome prevention behavior when they seeing it practiced by nurses in hospitals ${ }^{(31)}$.

Caraballo et al (2016) disagreed with the current study result and indicated that almost all mothers were aware of and practiced supine sleep to avoid the risk for suffocation if placed face-down, only a few mothers practiced prone sleeping position for their infants. ${ }^{(22)}$ Park (2012) disagreed with the present study as he indicated that more than two thirds of mothers used supine position, whereas only one third of them practiced either side-lying, prone, or a combination of two or three positions. ${ }^{(26)}$ A recent study conducted by Frey et al (2020) revealed that most infants were placed to sleep in the supine position before the health education, which is inconsistent with the current study result ${ }^{(32)}$. Bartlow et al (2016) and Laporte et al (2020) also were in contrast to the present study, they stated that the majority of infants were placed to sleep in supine position exclusively all the time. $^{(33,34)}$

In relation to room sharing without bed sharing, the present study revealed that the majority of mothers put infants to sleep in their own bed before health education. From the researchers' point of view, mothers explained that they need to be close to the infant for breast feeding and to stop infants' cries, while others mentioned that a separate bed for their infant was not safe and expensive. Isezuo et al (2017) mentioned that the majority of infants shared bed with their parents or sibling, which supported the current study result. (24)

The result of Fowler et al (2013) was congruent with the present study as they revealed that many mothers reported their feeling that infants are safer in the same bed with them than in a separate bed. (35) The result of Caraballo et al (2016) was the same as the current study result; they reported mothers shared bed with their infants regularly. ${ }^{(22)}$

The present study revealed that there was a significant improvement of total reported safe sleep practices after implementation of health education. This result may be explained that mothers became aware of relation between sudden infant death syndrome and sleep practices after health education. The findings of Frey et al (2020) were similar to the present study as they found that there was post intervention adherence and a significant improvement of mothers' safe sleep practices (32). Barsman (2015) clarified that there was a link between mothers' sleep practices and 
sleep practices that they saw in hospital setting because of role modeling and they were unable to change their practices in spite of health education. ${ }^{(36)}$

The present study clarified that mothers health beliefs about SIDS changed from negative beliefs before health education to positive beliefs after health education with statistically significant difference. This result can be clarified by the researcher that mothers had negative beliefs about sudden infant death syndrome before health education due to lack of knowledge about risk factors and prevention so, the believed that it is a hopeless condition. On the other hand, mothers' knowledge increased after health education so, their beliefs became positive. The result of Hidarnia et al (2016) was the same as present study; they concluded that there was a significant improvement in the health beliefs of women after intervention. ${ }^{(37)}$

The present study revealed that there was a relation between mothers' knowledge about sudden infant death syndrome, their health beliefs and safe sleep practices. Mothers who had good knowledge about SIDS had positive health beliefs and followed safe sleep practices for their infants. As a result, those mothers can reduce the risk of occurrence of SIDS to their infants. Kamal et al (2017) agreed with the current study; they found that the hygienic behavior of mothers was markedly influenced by their beliefs about the relation between childhood infections and hygiene. ${ }^{(38)}$

The findings of the present study clarified that there was a positive significant correlation between total mothers' knowledge and total reported safe sleep practices immediately after health education. There was a positive significant correlation between mothers' knowledge and total health beliefs about SIDS after health education. The researcher can illustrate this result as knowledge improvement after health education led to change of their beliefs from negative to positive and following safe sleep practices to prevent sudden infant death syndrome.

\section{Conclusion and recommendations}

Based on the results of the present study, it can be concluded that there was a positive significant effect of educational intervention on improving mother's knowledge, reported sleep practices as well as health beliefs about Sudden Infant Death Syndrome. Mothers' knowledge had a positive significant effect on their health beliefs. In addition, the mean scores of mothers' total health beliefs increased after health education. Mothers' health beliefs about Sudden Infant Death Syndrome 
changed from negative beliefs before health education to positive beliefs after health education. The improvement of knowledge and health beliefs motivated mothers and helped them follow safe sleep practices to reduce the risk of Sudden Infant Death Syndrome.

\section{Recommendations:}

Based on the findings of the present study, the following recommendations are suggested:

1. Educational training programs should be conducted for nursing staff in all hospital departments especially pediatric and obstetric departments about safe sleep recommendations to prevent SIDS.

2. Nurses should follow safe sleep recommendations especially supine sleep position in NICUs as they are role models for parents after discharge and they should provide mothers with information about these recommendations during antenatal period and after birth especially young and inexperienced mothers.

3. Future studies should investigate the efficacy of alternative educational programs for grandmothers who had a significant influence over adolescent mothers .
4. The media plays an important role in the change of knowledge and health beliefs so, it should be used to increase the awareness about SIDS and safe sleep recommendations.

5. Maternal and Child Health Centers should establish public health measures and educational programs about SIDS awareness, risk factors, preventive measures, and safe sleep recommendations for mothers or other caregivers .

6. This study should be replicated with more mothers at different geographical areas to generate larger statistical power with a diverse group of mothers and attain more generalization of rest

\section{References}

1. Newberry J. Creating a safe sleep environment for the infant: what the pediatric nurse needs to know. Journal of Pediatric Nursing 2019; 44 (2):119-22 .

2. Hitchcock C, Ruhl C. Nurses leading safe infant sleep initiatives in the hospital setting. Nursing for Women's Health Journal 2019; 23 (2):148-62.

3. Thomas G, Penny K, Stastny F. Encyclopedia of Infant and Early Childhood Development: Sudden Infant Death Syndrome. 2nd ed. Philadelphia: Elsevier Co., 2020; 296-304. 
4. Sarquella G, Zambrano D, Diaz V, Fernandez A, Ramon F, Campuzano O. Early detection of sudden infant death syndrome: Systematic neonatal ECG, genetic study and familial cascade screening. Journal of Electrocardiology 2019; 53(3):13.

5. Randall B, Thompson P, Wilson A. Racial differences within subsets of Sudden Unexpected Infant Death (SUID) with an emphasis on asphyxia. Journal of Forensic and Legal Medicine2019; 62(2):52-5.

6. Blix A. A possible cause of Sudden Infant Death Syndrome. Medical Hypotheses Journal 2020; 136(3): 109- 15.

7. Rosenstock I, Stretcher V, Becker, M. Social learning theory and the health belief model. Health Education Behavior Journal1988; 15(2): 175-83.

8. Rosenstock I. Historical origins of health belief model. Health Education Monograph Journal 1974; 4(2):328-35.

9. Moon R, Oden R, Joyner B, Ajao T. Qualitative analysis of beliefs and perceptions about sudden infant death syndrome in African-American mothers: implications for safe sleep recommendations. Journal of Pediatrics 2010; 157(1): 92-7.
10. Roehler D, Batra E, Quinlan K. Comparing the risk of sudden unexpected infant death to common causes of childhood injury death. Journal of Pediatrics 2019; 212(5): 224-7.

11. CDC WONDER On-line Database. Centers for Disease Control and Prevention, National Center for Health Statistics. Compressed Mortality File 1999-2014, released December 2016, from the Compressed Mortality File 1999-2015, Series 20, No. 2U, 2016.

12. Hauck F, Carlin R, Moon R, Hunt C. Textbook of Pediatrics. 1st ed. United States: Elsevier Co., 2020; 2167-76.

13. Sharaf M. Rashad A. Socioeconomic inequalities in infant mortality in Egypt: analyzing trends between 1995 and 2014. Social Indicators Research Journal 2017; 137(4):1185- 99.

14. El-Zanaty F. Hussein E. Shawky G. Way A. Kishor S. (1996). Egypt demographic and health survey 1995. Calverton: National Population Council and Macro International Inc.

15. Task Force on Sudden Infant Death Syndrome. SIDS and other sleeprelated infant deaths: updated 2016 recommendations for a safe infant sleeping Environment. Official Journal 
of the American Academy of

Pediatrics 2016; 138 (5):1225-32.

16. Mims J. Perceptions of Sudden Infant Death Syndrome among African American Women Living in SPA 6 of Los Angeles County.A Thesis submitted to the College of Nursing in partial fulfillment of the requirements for the degree of doctor of philosophy, the University of Arizona, 2014.

17. Dawson B D and Trapp R G: Reading the medical literature: Basic and Clinical Biostatistics. Lange Medical Book/ McGraw - Hill. Medical Publication Division, New York. 3rd ed., Ch. 7-9, PP 161-218 and Ch. 13, PP 305-314, 2001.

18. Martin J, Hamilton B, Osterman M, et. al. Births: final data for 2015.Natl Vital Stat Rep Journal 2017; 66(1): 1-70.

19. Vennemann M, Hense W, Bajanowski $\mathrm{T}$, Blair S.Bed sharing and the risk of sudden infant death syndrome: can we resolve the debate? Journal of Pediatrics. 2012; 160(1):44-8.

20. Colson E, Willinger M, Rybin D. Trends and factors associated with infant bed sharing: the National Infant Sleep Position study. JAMA Pediatrics Journal 2013; 167 (11); 1032-7.

21. Botia I, Peñarroya P, Izquierdo A, Sánchez J, Santamaria A. Sudden infant death syndrome: Do the parents follow the recommendations? Anales de Pediatría Journal (English Edition) 2020; 92 (4):222-8.

22. Caraballo M, Shimasaki S, Johnston K, Tung G, Albright K, Halbower A. Knowledge, attitudes, and risk for sudden unexpected infant death in children of adolescent mothers: a qualitative study. The Journal of Pediatrics 2016; 174(1):78-83.

23. Bezerra M, Carvalho K, Bezerra J, Novaes L, Moura T, Leal L. Factors associated with knowledge of mothers on Sudden Infant Death Syndrome. Esc Anna Nery Journal 2015;19(2):303-9.

24. Isezuo K, Adamu A, Jiya F, , Ibitoye P, Ugege M, Sani U, Yunusa E, Sanni M, Jangebe M.. Infant sleep practices and knowledge of sudden infant death syndrome among mothers of infants attending the paediatric clinics of a tertiary hospital in Sokoto, Nigeria. Journal of Scientific Research and Reports2017; 16(2): 1-10.

25. Elsobkey F. Mothers' health education based on health belief model to promote health of preterm infant related to sudden infant death syndrome. American Journal of Nursing Research 2018; 6(4):164-173. 
26. Park M. Knowledge, opinions, and practices of infant sleep position among parents. Military Medicine Journal 2012;177 (2):235.

27. Abdeyazdan Z, Moshgdar H, Golshiri P. Evaluating the effect of lifestyle education based on health belief model for mothers of obese and overweight school-age children on obesity-related behaviors. Iranian Journal of Nursing and Midwifery Research 2017; 22(3): 248-52.

28. Rungtiwa W, Wichit S, Wilawan P, Jarassri Y. Effects of a transitional care program on preterm infants and their mothers. Pacific Rim International Journal of Nurs ing Research 2012; 16 (1):94-102.

29. American Academy of Pediatrics Committee on Fetus and Newborn. (2018). Hospital discharge of the highrisk neonate. Journal of Pediatrics. 122(5):1119-26.

30. Moon R, Hauck F. Colson E. Safe infant sleep interventions: what is the evidence for successful behavior change? Current Pediatric Reviews Journal 2016; 12 (2): 67-75.

31. Fox M, Caccciatore J, Lacasse J. Child death in the United States: Productivity and the economic burden of parental grief. Death Studies Journal 2014; 10 (1):1-6.

32. Frey E, Hamp N, Orlov N. Modeling Safe Infant Sleep in the Hospital. Journal of Pediatric Nursing 2020; 50(1): 20-4.

33. Bartlow K, Cartwright S, and Shefferly E. Nurses' knowledge and adherence to sudden infant death syndrome prevention guidelines. Pediatric Nursing Journal 2016; 42(1):7-16.

34. Laporte P, Eymeric M, Patural H, Durand C. Optimizing the sleep position of infants and embroidered "I sleep on my back" sleeping bags in maternity hospitals. Journal of Archives de Pédiatrie 2020; 27(6): 297-303.

35. Fowler A, Evans P, Etchegaray J, Ottenbacher A, Arnold C. Safe sleep practices and sudden infant death syndrome risk reduction: NICU and well-baby nursery graduates. Clinical Pediatrics Journal 2013; 52 (5): 1044-53.

36. Barsman S, Dowling D, Damato E, Czeck P. Neonatal nurses' beliefs, knowledge, and practices in relation to Sudden Infant Death Syndrome riskreduction recommendations. Advances in Neonatal Care Journal 2015; 15(3):209-19. 
37. Hidarnia A, Kaveh M, Hajizadeh E, Askari A. Application of the health belief model and social cognitive theory for osteoporosis preventive nutritional behaviors in a sample of Iranian women. Iranian Journal of Nursing and Midwifery Research 2016; 21 (2): 131- 41.

38. Kamal M, El-Borgy M, Wahba M. Application of health belief model for hygienic behavior of mothers of hospitalized children in Alexandria. Journal of High Institute of Public Health 2017; 47 (1): 13- 21. 